\title{
Microcomputers in psychology laboratory courses
}

\author{
PETER BALSAM, WILLIAM FIFER, SUSAN SACKS, and RAE SILVER \\ Barnard College, Columbia University, New York, New York
}

\begin{abstract}
The implementation of a microcomputer-based laboratory curriculum is described and analyzed in terms of general guidelines for introducing computer-based instruction. Procedures are suggested for analyzing need, choosing a system, and implementing the project. Pedagogical considerations arising from the use of computer technology are also discussed.
\end{abstract}

In 1981, the Barnard psychology department introduced computers into its curriculum. In this paper, we describe our instructional use of computers and some of the issues that ajose during implementation of this project. This information should provide a useful framework for departments beginning to integrate computers into their instructional technology. We briefly describe (1) the general needs and benefits that encourage funding and development of computer-based laboratory courses; (2) the factors to consider in choosing hardware and designing physical space for computers; (3) a program for implementing computer-based instruction; (4) the functional uses of computers in the curriculum; and (5) some of the pedagogical issues that are raised by computer usage.

\section{NEEDS AND BENEFITS}

Barnard College is an undergraduate liberal arts college. Enrollment in the psychology laboratory courses consists primarily of undergraduate majors fulfilling departmental requirements and nonmajors meeting the college's laboratory science requirement. There are approximately 400 enrollments each year in the psychology laboratory courses. This level of demand creates the need for a variety of lab experiences. The department therefore offers 16 sections of lab courses in seven different subspecialties (developmental, learning, memory, perception, physiological, social, and tests and measurement) as well as a lab in statistics.

The need for all of these lab courses arises from our belief that "hands-on" experience is essential in science instruction. Prior to the acquisition of computers, we had been using specialized equipment in the labs (e.g., tachistoscopes, memory drums, relay equipment, calculators, stopwatches, etc.) that was difficult to main-

The project described here was supported by grants from the National Science Foundation (SER8103827) and the PEW Memorial Trust. Reprints may be obtained from P. Balsam, Department of Psychology, Barnard College, Columbia University, New York, NY 10027. tain and store. Additionally, weekly lab preparation and equipment setups had been very time consuming. The equipment we were using limited the topics we could teach and the number of students we could enroll, as well as the number and kind of independent student projects we could support. In addition, replacement costs were becoming exorbitant. Microprocessors would address all of these problems in most of our courses and would do so for less money than continuing to buy specialized equipment for each course. Because a microcomputer could serve as the basic instrumentation for several courses, laboratory preparation time could be minimized and lab classrooms used with greater flexibility.

Financial and pedagogical considerations aside, entering students have come to expect that computers will be an integral part of their college education; hence, part of maintaining an institution that attracts good applicants is providing computer use and instruction in the educational environment. To this end, the psychology department has served as a model and resource for other departments in the college as they begin to use computers.

\section{HARDWARE AND FACILITY}

Computer hardware and software change at a very rapid rate. When purchasing equipment, there is always the temptation to wait 6 months for the "next generation." Neither hardware nor software is functionally obsolete, however, so long as it does the job for which it is needed. The most important step in deciding on a computer system, therefore, is to carefully define the need that it is to fulfill. Once this has been done, equipment availability and financial considerations at the time of purchase will dictate the choice of system.

The considerations that went into our decisions are described below to provide an example of this process. The first step was to delineate in detail our specific needs, describing the kinds of inputs, outputs, timing, stimulus displays, and programs that would be necessary for particular courses. After a substantial amount 
of comparative shopping, we decided on TRS. $80 \mathrm{com}$ puters as the basis for our system. This decision was based on the availability of "plug-in" digital and analog $\mathrm{I} / \mathrm{O}$ interfaces, the variety of laboratory software available for these computers (Perera, 1981), the price, and, most important, the availability of service and maintenance.

The range of microcomputer costs is from less than a hundred to a few thousand dollars. Although more expensive systems can generally do more tasks in less time, smaller systems may often be adequate. For example, we originally started with $16 \mathrm{~K}$ TRS -80 Model I computers with cassette storage. External inputs activated optoisolators to produce keyboard input (Perera, 1980), and external outputs were controlled by the monitor(Clower \& Calabraro, 1983). Today, with computers selling for less than $\$ 100$, such a primitive system could probably be assembled for under $\$ 250.00$. Even such a simple system could run most basic psychology experiments. Our facility now consists mainly of single-disk TRS-80 Model IIIs with 48K of RAM and digital I/O interfaces.

The laboratory classroom itself was designed especially for microcomputer-based laboratory courses. There is a central classroom area surrounded by 14 smaller rooms (approximately $5 \times 8 \mathrm{ft}$ ). Each of the 14 small rooms contains a microprocessor and interface. There is a control panel in the central room that is wired to the small rooms so that four lines go from the central panel to all cubicles and four separate lines go from the central panel to each cubicle. This was designed to provide for future flexibility in implementing a networked system (see Eckerman, 1983).

\section{IMPLEMENTATION PROCESS}

When implementing computer-based instruction, a program must be developed for systematically introducing the new equipment. This involves two stages: expanding the uses to which the microcomputer can be put, and gradually increasing the number of users working on the system. In the following paragraphs, we suggest a process for achieving these goals. The aspects of implementation to be considered include faculty training, developing support staff, hardware and software upgrading, program development, and budgetary projections.

The best way to induce faculty to learn the new system is to offer a stipend or honorarium for participation in a training course. In such a course, the basic operation of the computer should be covered first and immediately followed by a topic that is of immediate and obvious use to the faculty. We have found that faculty are all highly motivated to learn about word processing. Documentation and/or programs that describe existing software should then be shown to the faculty in demonstration sessions. Next, participants' interests should be surveyed, and the remaining topics of the course should be tailored to the particular com- puter needs of the group. These might include data base management for student grades, graphics, statistical packages, or on-line control of experiments.

To introduce computers into the classroom situation, it is best to work with the faculty with the greatest expertise for initial implementation of the project. After one or two people successfully use the computer for a particular function, other faculty discover the benefits that their colleagues are experiencing, such as less time on lab setup and equipment repair and more time for students and for their own research. These benefits serve as a good motivator for expanding computer use.

Another important feature of implementing computerbased instruction is the development of a support system for hardware (Schneider, 1981) and software acquisition, equipment maintenance, supervision of equipment use, and tutoring of students. We have found that computer science majors can provide the backbone of such a system. These assistants can act as tutors for other students and perform hardware maintenance.

Implementation of software should also proceed systematically. Initially, it is best to use existing programs. Next, existing software can be modified for particular needs. Finally, custom software can be developed de novo. Students who have served as tutors or assistants can often write programs for specific course needs.

It should be noted that once your software works, there may be little reason to upgrade, even when an enhanced product appears on the market (especially if it is incompatible with your software). For example, if a text editor is adequate for your purpose, there is no need to change to a more versatile editor. In a similar vein, it has been our experience that hardware upgrading has been primarily in the direction of expanding peripherals, such as changing from cassette to disk storage, increasing RAM, upgrading from one disk to two, and obtaining more and better printers. It has not been necessary to change the kind of microprocessor even though faster and more versatile models have been introduced. In fact, there is great advantage in having a whole department utilizing a single model of microprocessor, because programs and general knowledge can readily be exchanged among faculty and students.

Finally, the budget should be planned in two phases: (1) initial acquisition cost and (2) maintenance. Initial acquisition cost should be aimed at a "bare-bones" system that is flexible enough for later expansion. In subsequent budgets, one should include at least $10 \%$ of initial cost for maintenance, and then money for upgrades should be allocated as a final priority.

\section{COMPUTER USAGE}

Computers are currently used in four major ways in our psychology curriculum. The TRS-80s serve as the major instrumentation for lab courses in learning, human memory, and perception. Stimulus display, data acquisi- 
tion, and analysis are all controlled, depending on instructional goals, partially or wholly by the microcomputer. Second, students are being taught to use the computer for data analysis in the statistics and psychological measurement courses. This consists mainly of learning to use "canned" statistical packages to analyze data. Third, the computers are used for more traditional but limited CAI activities. For example, in perception and in learning classes, students study various quantitative models of behavior by performing simulations. Similarly, in statistics, various principles can be dynamically illustrated with computer graphics. The fourth use of computers has been as data-recording devices in learning, social, and developmental labs. Students use keyboard inputs to record ongoing or videotaped behavior. Recently, we have begun to use portable TRS- 80 Model 100 computers for data recording and the Model IIIs for data reduction and analysis.

Although the four functions described above have been the major focus of the project, several other uses have also developed. The faculty have come to use word processing programs to write class materials, exams, and articles. Students engaged in independent research projects have also been using the computers for word processing. Finally, faculty and staff have recently begun to use the computers for record keeping (e.g., bibliographies, grades, etc.).

\section{PEDAGOGICAL CONSIDERATIONS}

Microcomputers have improved our laboratory instruction in many of the ways common to CAI programs (Taylor, 1980). The computer's capacity for immediate feedback, self-paced instruction, graphic representations, and analysis of student protocols has enhanced learning in many of our courses. Additionally, it has been our experience that student enthusiasm or involvement is not diminished by the use of computers for instruction, as some have suggested (cf. Taylor, 1980). In fact, over the past 2 years, we have been conducting attitude surveys in our courses, and the results indicate a positive attitude on the part of students and faculty toward the new technology.

Several issues must be considered in order to use computers to their greatest advantage in teaching. Perhaps the most difficult issue has been making decisions about how much the computer should do for students. The computer can be programmed to give instruction, run experiments, collect data, summarize the data, and do statistical tests. If the computer does all this, then what is left for the student? In each class, we have had to be clear about what specific activities we want students to perform. For example, if we want them to understand how to compare two groups of subjects, then they must be presented with data prior to presenting the results of a statistical test. If we want them to appreciate individual differences, then they must be exposed to data before the data are summarized, and so on.

At times this decision is easy, at times not. Often the best way for students to understand an experimental method is for them to manually implement each step of the procedure. On the other hand, this must be balanced against the tedium and imprecision of each individual's manually doing tasks. We have found that, as a rule, we can balance these needs by initially having students arrange all experimental events and record data by hand. Gradually, more control can be assumed by the computer, thus freeing the student to focus on data analysis and interpretation. As a general rule, these decisions are made by emphasizing the process to be mastered by the student.

A second issue of some pedagogical importance is how much time to spend on teaching students about computers rather than on the content of the course. In one course, we experimented with teaching some BASIC programming. We found that this worked to the detriment of learning about the main topic. As a result, we now devote little time to teaching programming. We do explain in general terms how a computer works and interfaces with other equipment. Additionally, we encourage those students who have already learned to program to examine the software and to modify it for individual projects.

Overall, the integration of computers into our laboratory curriculum has produced many benefits. We now support many more students in labs and independent projects than had previously been possible. Our lab curricula have been expanded and are now easily updated, modified, and improved.

\section{REFERENCES}

Clower, P., \& Calabraro, P. (1983, October). Seeking a cheap output? Microcomputing, pp. 82-84.

ECKe RMAN, D. (1983, November). Laboratory control with Apple IIs networked to a hard disk. Paper presented at the meeting of the Psychonomic Society, San Diego.

Perera, T. B. (1980). Universal one- and two-component interfacing techniques. Behavior Research Methods \& Instrumentation, 12, 236-237.

Perera, T. B. (1981). A laboratory in experimental psychology using the TRS-80. Behavior Research Methods \& Instrumentation, 13, 195-197.

Schneider, W. (1981). Basic computer troubleshooting and preventive computer maintenance operation. Behavior Research Methods \& Instrumentation, 13, 153-162.

TAYLOR, R. P. (Ed.). (1980). The computer in the school: Tutor, tool, tutee. New York: Teacher's College Press. 